\title{
The Role of Leadership and Strategic Decision on Regional Development in Developing Countries
}

\author{
Submitted 05/08/19, $1^{\text {st }}$ revision 15/09/19, $2^{\text {nd }}$ revision 13/10/19, Accepted 06/11/19
}

\begin{abstract}
Ibrahim Krasniqi ${ }^{1}$, Bedri Statovci ${ }^{2}$
Abstract:

Purpose: This research paper is focusing on the role of leadership and strategic approach for the best institutional model toward balanced regional economic development (RED) in developing countries. The research paper examines the cohesion among leadership models and decision making structures toward strategic model for regional economic development in Kosovo. Final purpose is setting up the suitable decision making structure across all regions in the country that through proactive and authentic leadership, as well effective institutional structures creates capacity in each region for better utilization of the resources.

Design/Methodology/Approach: The paper methodology used a mixed-methodological approach including both qualitative and quantitative data collection and appraisal, which included desk review covering existing literature at national and international level, semistructured interviews with key stakeholders, relevant reports and other related documents.

Findings: The research paper has finded that there are significant relationships among leadership role, organizational structures and regional development. Acording to the paper a suitable leadership model followed by responsible institutional framework and decision making structures is usualy the most important factor influencing growth at the regions. Actually in Kosovo regions and municipalities lack the capacities to create an effective environment for private sector development and job creation for all communities. The paper analysis shows that both-leaderhsip and decision making structure amplifies the institutional structure and institutional resources' effect on the better performance of regions.

Practical Implications: The practical implications deriving from this research concludes that future approach to RED should be based on balanced distribution of responsibilities between different governmental levels with clear vision and leadership, as well as with much more advanced institutional structures and detailed work design. This means that creative leadership will ensure not only better performance in economical development aspects but meanwhile will adjust better to external changes and work more efficiently.

Originality/Value: The research paper shows its originality in a specific case study and the value of this is finalized with the regional economic development model that will serve as one stop shop at different regions supporting the economic and overall development.
\end{abstract}

Keywords: Leadership, strategic management, regional development, sustainability.

JEL codes: $R 5, R 50$, R58.

Paper type: Research article.

${ }^{1}$ University Haxhi Zeka, Faculty of Business, Peja, Kosovo, Corresponding author ibrahim.krasniqi@unhz.eu;

${ }^{2}$ University Haxhi Zeka, Faculty of Business, Peja, Kosovo, bedri.statovci@unhz.eu 


\section{Introduction}

Nowadays the key objective of regional economic development (RED) is to decrease the disparities among the regions with different development level, as well to ensure through modern leadership models and simplified institutional structures sustainable development of the country. Those processes ar enhanced by regional economic development strategies and implementation plans that enables a proactive approach.

The paper aims to explain the leadership role on better functionalization of institutions and regional structures with purpose to increase the interaction among all stakeholders to facilitate entrepreneurship and support economic and bussines development. Strong leadership is directly linked with clear strategic management and this is precondition to the regional economic development circles. Those circles are created and managed by transformational leadership that leads the process on new institutional structures which meet and well anticipate the external environment and factors in order to facilitate the business operation and supports the full resource endowment in regions (Stimson et al., 2003). This virtuous circle will enhance the regional capacities and decision making structures to more flexible approach to resources, funds and opportunities that finaly will push less developed regions to be more competitive and bussines oriented.

Figure 1: Role of Leadership and Sustainable Regional Development

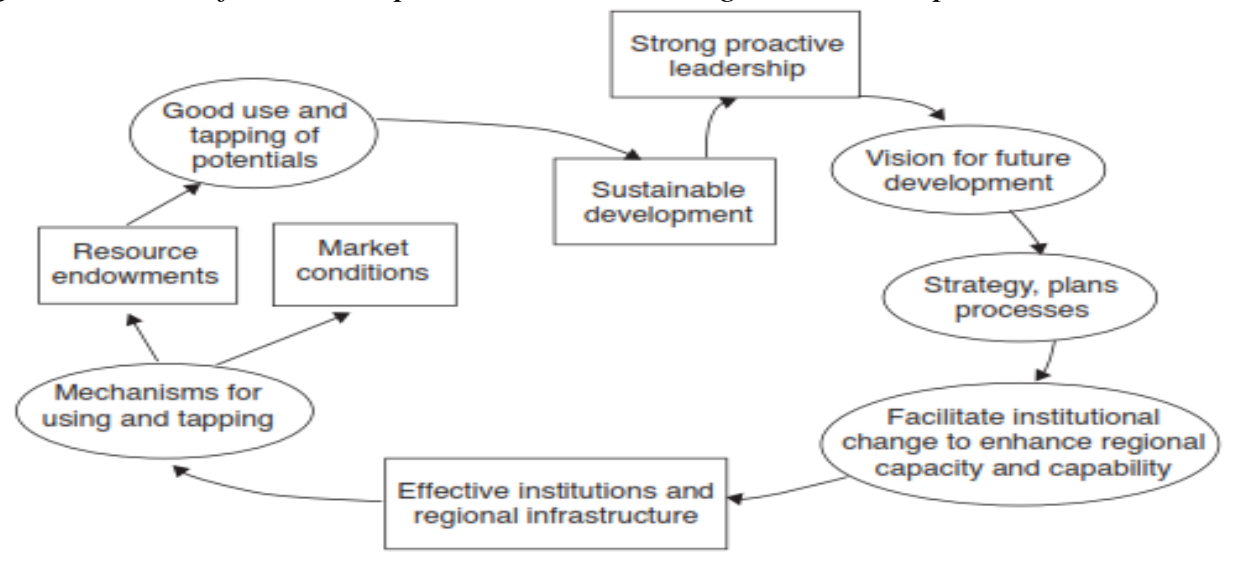

In our research we will be focused in Kosovo as a new and less developed country aiming to show that new lewadership model and framework can increase substantialy the economic development and equalize the regional disparities. Kosovo's citizens are the poorest in Europe with a per capita GDP €3,332 in 2017. An unemployment rate of $31 \%$ and a youth unemployment rate near $60 \%$ in a country where the average age is 26 years old, encourages emigration and presents a significant source of informal, unreported economy. Kosovo enjoys lower labor costs than the rest of the region (Kosovo Economic Profile, 2017). The National Development Strategy (2016-2021) aims to address the key obstacles in the overall 
development of Kosovo. These obstacles largely correspond with the obstacles faced in sustainable economic development and include the challenges encountered in the strategic vision, coordination of development policies and institutional processes, as identified by various national and international stakeholders.

Therefore, lessons learned from the previous financial assistance, have to be considered and translate in the future strategic steps for the regional economic development including:

- The need for a more strategic and holistic approach to Regional Economic Development and further support in improving the business environment and infrastructure throughout Kosovo.

- The need for new leadership approach and revising the institutional structures (RDAs, ARDA, and other related institutions) for managing and using financial resources available for economic development at regional and local level.

- Need for new organizational structures, able to face the changes and challenges toward economic development and business support.

In this context, the elaboration of an adequate strategy for Regional Economic Development is the basis for reducing regional disparities. Strategic management approach through a new leadership model will be crucial for the sustainable regional economic development of the country (EU Regional Development Strategy, 2016).

\section{Literature Review}

In recent years the attention to the regional development questions and regional leadership is drastically increased (Collinge, Gibney and Mabey, 2010a; Gibney, 2014; Normann, 2013). Manny researchers dealing with regional development in general and specific leadership models in particular have tried to incorporate the role of leadership as a variable within endogenous growth models (Stimson et al., 2009), while some other policy-oriented researchers have asked: Under which circumstances do government agencies take on the place leadership challenge, and how do those responsibilities sit with other dimensions of authority, and the private sector?

Neoclassical economics became one of the important bases of regional development policies as it had been applied to the analysis of regional imbalances and the manner by which such problem can be resolved (Niskanen, 2005). While the classical economists have concerned themselves with the exploration of the formation, distribution and utilization of the national surplus, the "Neoclassicists" focused chiefly on the problem of resource allocation.

Richardson (1973) explains the claim of neoclassical economics that regional disparities in terms of supply and demand of factors of production (labor, capital, 
technology) or commodities will even out inevitably given the sufficient increase in the accessibility between regions and consequently by the mobility of these production factors and commodities. According to the theory, regional imbalances in supply and demand manifest themselves in differences in prices of these factors of production and commodities. This is important as the theory assumes that equal factor prices would lead to equal income levels (Lewis, 1955).

The other view, so called balanced growth strategy and policy (Rosenstein-Rodan, 1943), argues that concentrating resources only in a few sectors especially those which have the absorptive capacity for modern technology would undermine the potentials of the other sectors (Nurkse, 1963). This is especially in cases where the other sectors comprise the major component of the economy and particularly difficult in cases wherein the sectors are closely linked and interdependent that lifting one or few sectors would risk others to be neglected in the process. Those who argue against balance growth contends that the likely resources needed to implement large-scale and simultaneous investment efforts in a developing country may be found wanting (Kösecik, 2005).

Hirschman's (1958) contention is that the inputs necessary for balance to occur such as capital, entrepreneurship, regulating policies and informational mechanisms on demand, supply and prices that are to be applied simultaneously within and among all the regions are very limited in underdeveloped countries. In the past decades, the use of clusters or clustering, networks and other related terms in regard of RED have emerged. The use of the term cluster has been popularized with the introduction of Porter's approach (Porter, 1998) in the term and in the context of competition of firms and locations. He defined a cluster to mean "a geographical proximate group of interconnected companies and associated institutions in a particular field, linked by commonalities and complementarities". Nowadays, Regional Economic Development is a strategic approach for creating sustainable development through the regions, as it became an important model for most of the European and Balkan countries.

\subsection{Regional Economic Development, Experiences and Lessons Learned}

In most countries, strategic management approach for regional economic development began in the period 1950s and 1960s. The post-war period of reconstruction was characterized by strong economic growth, fiscal expansion, and low unemployment. The debate over regional development started and the research on the interdependencies of sectorial policies and the impacts on regions facilitated cooperation of cross-sectorial policies (Yuill et al., 2008). Currently, Kosovo neither has a regional development policy nor a law on regional development and adequate strategies, leadership and institutional structures. In many countries, socio-economic disparities persist, though there are differences in intensity and in how these problems are perceived. In some countries, disparities are considered to be relatively limited and do not justify major regionally targeted interventions (Austria, Denmark, 
Luxembourg, and the Netherlands). Policy responses to these disparities are divided into three categories:

a) keeping the main policy focus on regional disparities (Germany and Italy);

b) providing support for lagging regions although it is not the main policy focus (Finland and Japan);

c) focusing on national economic growth in spite of internal disparities (Czech Republic and Hungary).

The traditional focus on inter-regional disparities has been complemented with more detailed intra-regional disparities, an urban-rural divide, and concern about the decline of distressed areas (old industrial areas, rural areas, urban poverty pockets), (Anderson, 2005). The objectives of regional policy and the level in the legislative hierarchy at which they are set vary considerably. However, in some countries (Belgium, United Kingdom) there is no overarching strategy for regional development policy at the national level because policy responsibility is devolved to the subnational level.

\section{Table 1. Typology of national regional policies in West Europe}

\begin{tabular}{ll}
$\begin{array}{l}\text { Prominenet regional disparities-regional } \\
\text { development policy }\end{array}$ & $\begin{array}{l}\text { Finland, Italy, Germany, Spain, Norway, } \\
\text { Sweden }\end{array}$ \\
\hline $\begin{array}{l}\text { Diverse territorial challenges-regional } \\
\text { cometittiveness policy }\end{array}$ & France, United Kingdom, Belgium \\
\hline $\begin{array}{l}\text { Limited regional disparities-national } \\
\text { cometittiveness policy }\end{array}$ & $\begin{array}{l}\text { Switzerland, Austria, Luxemburg, } \\
\text { Netherland, Denmark }\end{array}$ \\
\hline $\begin{array}{l}\text { Diverse geofraphical issues- national } \\
\text { development policy }\end{array}$ & Slovenia, Ireland, Malta, Portugasl, Greece \\
\hline $\begin{array}{l}\text { Widening regional disparities- national } \\
\text { growth/ development policy }\end{array}$ & $\begin{array}{l}\text { Estonia, Chech Republik, Bulgaria, } \\
\text { Lithuania, Latvia, Hungary }\end{array}$
\end{tabular}

\section{Methodology, Approach and Data Collection}

During this work the documentation required for the evaluation was provided by different institutions, and in some cases, the additional information was gathered during field visits. The stakeholders and respective institutions including RDAs were cooperative and they were systematically consulted and interviewed. The evaluation methodology primarily used a mixed approach based on qualitative and quantitative data collection and appraisal, which included:

- Desk reviews of existing literature at national and international level.

- Semi-structured interviews with key.

- Completion of data from semi-structured interviews and group discussions.

- Regional development strategies.

- Reports on business environment in Kosovo.

- Grant materials and reports produced. 


\subsection{Methodological Tools for Field Assessment}

The methodology used included both qualitative and quantitative approach, face-toface meetings and interviews as well as primary and secondary data collection. The instruments and tools used include face-to-face discussions and semi-structured interviews as presented in the annex. The flow of the discussion is based on a strategic thinking approach. In the synthesis phase, the comprehensive analysis is prepared based on relevant information collected from literature, key informants, and stakeholders. In the desk review, the research was oriented in three directions:

- Analysing all available documents relevant for the assignment.

- Analysing the legal framework related to regional development in Kosovo.

- Analysing the primary data taken from consultations and field work.

\subsection{Problem Statement}

Regional development reflects not merely the outcome of "market forces," but also complex political, institutional, and cultural factors that shape how "economic" decisions are made. Comprehensive regional policies increasingly find their role as complementary to national economic and structural policies by helping generate growth and wealth in the regions. Currently, Kosovo neither has a regional development policy nor a law on regional development and adequate strategies as stated above. Failure to define clear policies on regional development brings problems expressed in the form of:

- regional disparities in terms of socio-economic indicators;

- the lack of socio-economic development policies for greater competitiveness between the regions themselves;

- lack of linkage with government sectorial development policies and activities in region levels and non-stimulation of inter-regional, crossborder, and international cooperation;

- non-classification of Kosovo according to NUTS statistical regions;

- lack of necessary mechanisms for access to EU development funds and other;

- non-existence of clear mechanisms (respective institutions) for regional development management.

\subsection{SWOT Analysis and Factors Affecting the Problem}

The SWOT analysis approach (also referred to as the "design school model"; Mintzberg) seeks to address the question of strategy formation from a two-fold perspective, that is, from an external appraisal (of threats and opportunities in an environment) and from an internal appraisal (of strengths and weaknesses in an organisation). The two perspectives can be differentiated by the different degree of 
control attainable within each. In this regard, the regional development in Kosovo has several strengths and weaknesses, but as well, there are opportunities and threats as presented below in Table 2:

Table 2. Regional Development in Kosovo-SWOT Analysis

\begin{tabular}{|c|c|}
\hline $\begin{array}{l}\text { Strengths } \\
-\quad \text { Diversified economic structure } \\
-\quad \text { Strong academic system } \\
-\quad \text { Centre of expertise and other } \\
\quad \text { knowledge resources } \\
\text { - } \quad \text { Location and traditions } \\
-\quad \text { Unique natural conditions } \\
-\quad \text { Rich cultural traditions } \\
-\quad \text { Bilingualism } \\
-\end{array}$ & $\begin{array}{l}\text { Weakness } \\
-\quad \text { High unemployment } \\
-\quad \text { Weakness of marketing } \\
-\quad \text { Lack of co-operation } \\
-\quad \text { Weak administrative structures } \\
-\quad \text { Weak regional profile } \\
-\quad \text { Corruption } \\
-\quad \text { Political tensions }\end{array}$ \\
\hline 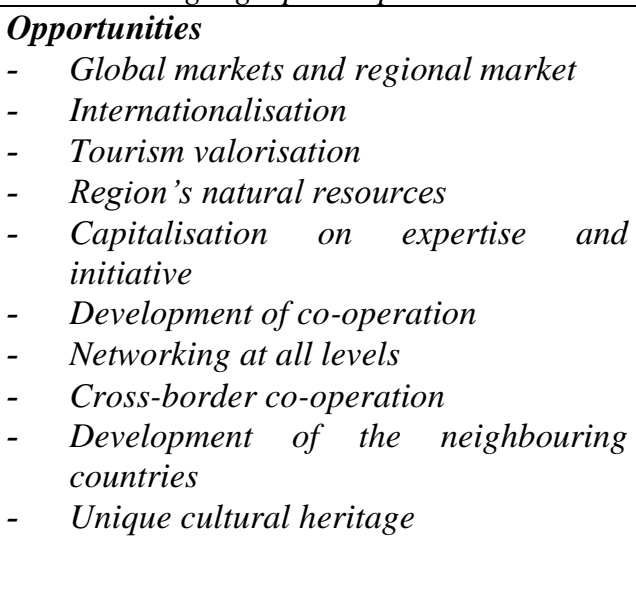 & $\begin{array}{l}\text { Threats } \\
\text { - Persistent high level of unemployment } \\
\text { and marginalisation } \\
\text { - One-sidedness of economic life (in } \\
\text { particular within growth areas) } \\
\text { Disruption of co-operation and } \\
\text { isolation and } \\
\text { Distorted regional policy } \\
\text { - Depopulation of the country-side } \\
\text { - Environmental problems and } \\
\text { catastrophes } \\
\text { Continuous tensions with neighbouring } \\
\text { Serbia } \\
\text { Instable political situation in } \\
\text { neighbouring countries }\end{array}$ \\
\hline
\end{tabular}

\section{Data Analysis}

During research, field assessment served to collect information and experiences from stakeholders as well as proved to be an opportunity to discuss the possible future scenarios for the framework of regional development. In the field assessment large number of institutions and organizations are involved and consulted. Semistructured interviews and questionaries as research tool with open question during research were focused on the:

- Verification of the efficiency and effectiveness of the current model based on its leadership, organisation, activities, business support, business satisfaction and potential to be used in the future.

- Assessment of the situation with regard to regional economic cooperation and joint project development. 
- Functioning of the ARDA and RDAs in the specific regions, support, success, and failure cases on dealing with Regional Development projects including challenges and needs.

- Common projects developed and implemented.

Table 3. List of stakeholders consulted and interviewed

\begin{tabular}{llllllll}
\hline No. & Institution & No. & Institution & No. & Institution & No. & Institution \\
\hline 1 & MLGA & 8 & MESP & 17 & $\begin{array}{l}\text { Association of } \\
\text { Municipalities }\end{array}$ & 24 & $\begin{array}{l}\text { Shtime } \\
\text { Municipality }\end{array}$ \\
\hline 2 & ARDA & 9 & $\begin{array}{l}\text { Pristina } \\
\text { Municipality }\end{array}$ & 18 & $\begin{array}{l}\text { Ministry of } \\
\text { Economic } \\
\text { Development }\end{array}$ & 25 & $\begin{array}{l}\text { Mitrovica } \\
\text { Municipality }\end{array}$ \\
\hline 3 & RDA East & 10 & $\begin{array}{l}\text { Ferizaj } \\
\text { Municipality }\end{array}$ & 19 & $\begin{array}{l}\text { Ministry of Trade } \\
\text { and Industry }\end{array}$ & 26 & $\begin{array}{l}\text { NGO Centre- } \\
\text { CESD }\end{array}$ \\
\hline 4 & RDA West & 11 & $\begin{array}{l}\text { Gjilan } \\
\text { Municipality }\end{array}$ & 20 & $\begin{array}{l}\text { Prime Minister } \\
\text { Office }\end{array}$ & 27 & NGO South \\
\hline 5 & $\begin{array}{l}\text { RDA } \\
\text { South }\end{array}$ & 12 & $\begin{array}{l}\text { Gjakova } \\
\text { Municipality }\end{array}$ & 21 & $\begin{array}{l}\text { Chamber of } \\
\text { Commerce of } \\
\text { Kosovo (KCC) }\end{array}$ & 28 & NGO North \\
\hline 6 & $\begin{array}{l}\text { RDA } \\
\text { Centre }\end{array}$ & 13 & $\begin{array}{l}\text { Prizren } \\
\text { Municipality }\end{array}$ & 22 & $\begin{array}{l}\text { Ministry of European } \\
\text { Integartion }\end{array}$ & 29 & NGO East \\
\hline 7 & $\begin{array}{l}\text { RDA } \\
\text { North }\end{array}$ & 14 & $\begin{array}{l}\text { Mitrovica North } \\
\text { Municipality }\end{array}$ & 23 & Zvecan Municipality & 30 & $\begin{array}{l}\text { University of } \\
\text { Peja }\end{array}$ \\
\hline & 15 & NGO West & & & $\begin{array}{l}\text { University of } \\
\text { Pristina }\end{array}$ \\
\hline
\end{tabular}

Based on the primary data gained and analysed at least three different groups of thoughts about the achievements, actual situation, and future developments are differentiated.

The first group of identified stakeholders includes ARDA and RDA representatives, who describe the situation as good and they mainly listed activities and success. The second differentiated opinion is that leadership and structures (RDAs) have not been sufficiently involved so that they can exert a significant impact in their role as catalysts and initiators of local and regional development initiatives. This has weakened their position and biased the understanding of their real role and their visibility on a local and regional scale. The third group includes the stakeholders without a clear opinion about RDAs and Regional Development.

\subsection{Main Findings and Evaluation}

The research based on the role of leadership and Regional Development Assessment in Kosovo shows that the situation is not satisfying all relevant stakeholders as described above. The Association of Regional Development Agencies (ARDA) has evolved as an umbrella organisation founded by the RDAs in 2017 with the following objectives: 
- to coordinate the cooperation between the economic regions in Kosovo and respective Agencies;

- to represent common and specific issues on the national level;

- to attract financial resources on a national level in implementing REDs to promote Regional Rural Development to consolidate the RED strategies and priority projects;

- to manage the knowledge and skills in RDAs for implementing common activities.

\subsection{Regional Economic Development, Structures and Leadership}

Regional Development is emerging in Kosovo as an important model for generating sustainable regional development while also helping mitigate the social costs of transition, particularly by addressing unemployment in an overall context in which capacities to design and develop concepts for regional initiatives and to enhance investments and employment remain limited. In this concept the new regional structures and leadership model should support the new ideas and strategies that contribute to regional collaboration, innovation and prosperity. Regional development policy largely focuses on longer term challenges such as:

- development, restructuring, people and place focused developments;

- mainstreaming poverty alleviation, developing local resilience;

- tapping the potential of local resources to the fullest;

- developing effective monitoring indicators;

- affecting guided involvement of the private sector including NGOs;

- sustaining the environment and spatial planning.

The key challenge facing many developing regions around the country is the need to respond to population and economic growth. In that sense it is important to take into account three important pillars for equal regional development as below in Figure 1:

Figure 1. Components of Regional Development

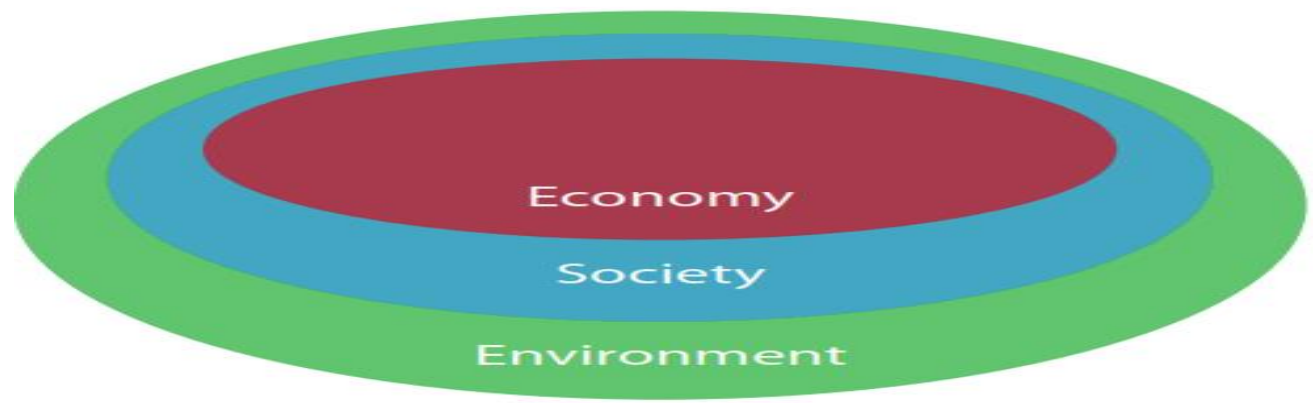




\section{a. Economy}

To underpin economic growth, Kosovo needs a modern and sustainable economic infrastructure. Kosovo, as small country, needs to build synergies among regions and through such synergies, it could support regional development.

\section{b. Society}

Sustainable communities are places where people want to live, work and play, now and in the future. They meet the diverse needs of existing and future residents, are sensitive to their regions, and contribute to a high quality of life. Balanced growth and appropriate policies are necessary to govern these dynamics.

\section{c. Environment}

Regional projects, specifically in fields of waste management, water treatment, and other related issues, helps to improve the quality of the environment, which in turn can make an important contribution towards achieving a better quality of life. If current rates of waste production continues it is forecasted that following the current trend, municipal waste arising will increase by almost $50 \%$ by 2020 .

\subsection{Strategic Scenarios for Regional Economic Development}

Based on research done the country should immediately address the regional economic development issue through shared strategy that should aim toward:

a. The reduction of the potential regional inequality, especially by stimulating balanced development and the revitalisation of marginalised.

b. The increase of the competitiveness of regions by strengthening their leadership capacity for innovation, optimal use and valorisation of the natural wealth, human capital and economic characteristics of different regions.

c. The establishment of institutional structures and mechanisms to build solid linkages with government sectors and development.

d. The preparation of the institutional framework to meet the requirements of integration into EU structures and to ensure access to financial assistance.

Different actors are involved in this matter. Regional development sees the involvement of and requires coordination among different institutional levels for its governance. The approach on how coordination among different levels of engagement is achieved can be summarised into three possible alternatives.

The first scenario-Balanced Regional Development (BRD) envisages a balanced distribution of responsibilities between the central government and the territorial government.

The second scenario- Bottom-up Regional Development (BURD) considers the possibility for the central government to delegate part of its proper functions to the regions and as they are not administrative units, this delegation should be carried out 
through a positive and effective cooperation among the municipalities and with the assistance of dedicated agencies.

The third scenario- Top-Down Regional Development (TDRD) considers the possibility of a centralised mechanism for Regional Development where the Central Government designs, plans and implements, with a certain grade of consultation and involvement of local levels, a regional development strategy allocating funds using the fiscal lever, promoting projects, and favouring the development of social services and infrastructures.

In synthesis, the impact of the three scenarios on the principle for an equitable, sustainable, and inclusive Regional Development are considered as follows in Table 4:

Table 4. Analysis of the Scenarios' alternatives-Synthesis

\begin{tabular}{lllllll} 
Scenario & & Programming & Concentration & $\begin{array}{l}\text { Decentralized } \\
\text { cooperation }\end{array}$ & Partnership & $\begin{array}{l}\text { Additionality and } \\
\text { co-financing }\end{array}$ \\
\hline $\mathbf{1}$ & Balanced & Medium-high & Medium & High & High & High \\
\hline $\mathbf{2}$ & $\begin{array}{l}\text { Bottom } \\
\text { UP }\end{array}$ & Medium-low & Low & Low & Low & Medium-low \\
\hline $\mathbf{3}$ & $\begin{array}{l}\text { Top } \\
\text { Down }\end{array}$ & Medium & High & Low & Low & Medium-low
\end{tabular}

\section{Future Steps for Regional Economic Development in Kosovo}

In order to accommodate the structural context in Kosovo, a participative approach to learning and implementing strong ownership by members, and a bottom-up perspective to regional development needs to be embraced. There is no a single theory, method or formula that can be used to ensure an effective and smooth pattern for the implementation of the Regional Development implementation in Kosovo. Goal for the regional policy should be to increase the weak regions' ability to increase the economic integration intervening with more intensity to connect them to the global economy and export possibilities. Skills and performance are naturally related. The goals of this phase are:

- The setting up of a common set of achievable results.

- The establishment of the role, level of ownership, responsibility and commitment of all the partners involved.

- The design of the best arrangement for decision-making, allocation, and flow of financial resources.

The support for Regional Development is not only in the provision of financial resources, but also in the capacity to plan, design, and implement technical assistance into a continuous learning mechanism. Municipalities and their regional development governing bodies should act under a well-established result-based framework. This would allow measuring performance and compliance of each 
region and allow intervening where it is necessary for the strengthening of capacities along the project cycle.

Table 5. Regional performance Matrix

\begin{tabular}{|c|c|c|c|}
\hline & 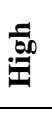 & $\begin{array}{l}\text { Funding and technical } \\
\text { assistance can exceed the } \\
\text { expectations }\end{array}$ & $\begin{array}{l}\text { Play a leading role in the RD } \\
\text { establish good practices and } \\
\text { lessons learned }\end{array}$ \\
\hline \multirow{2}{*}{ हूँ } & فَ & $\begin{array}{l}\text { Investing in human } \\
\text { resources to improve the } \\
\text { capacities on the Regional } \\
\text { Development Cycle }\end{array}$ & $\begin{array}{l}\text { Additional investments for the } \\
\text { removal of environmental } \\
\text { constrains and bottlenecks }\end{array}$ \\
\hline & & Low & High \\
\hline
\end{tabular}

The matrix is only for expositive purpose and serves as base for the development and implementation of a results-based mechanism for the allocation of resources for investments on human capacities.

\subsection{Recommended Alternatives}

To consider the possible alternatives for the institutionalization of Regional Development, it is necessary to consider what regional development should do and what it has to produce. This means finding a room where composition of different interests can be harmonized and optimized. This is possible when:

- The five principles analysed above are embodied into the process.

- Forms are part of broad place-based strategies that focus resources at a specific location.

- Promote coordination across different actors.

- Helps to overcome fragmentation and overlaps in government activities.

- Enhance outcomes from investments.

To address holistically the different aspects as presented above, the first scenario appears the most suitable for implementing Regional Development in the Republic of Kosovo. The framework has the responsibility to increase the dialogue and the cooperation among the different actors at both vertical and horizontal level. Cooperation and dialogue is the most effective way to promote development and generate the necessary density of "interactions" for change. Therefore, regional development policy should include measures to address institutional weaknesses and mechanisms to intervene for reducing gaps within an evidence-based mechanism. Shaping the institutional framework for Regional Development in Kosovo from the existing situation in a balanced mechanism requires a deep redesign of the role and responsibilities of each component. Each stakeholder including national government and municipalities, have to recognize the importance of Regional Development for the future of the country in order to achieve the aim of a balanced equitable and inclusive development. 
Institutional structures need to coordinate their efforts and policies embedding them into the new regional development framework. The national development fund would help accelerate the mechanism of regional development. Municipalities need to reconsider their role in regional development. There is a need to increase cooperation between municipalities and the local stakeholders. Dialogue, linkages, and partnerships between municipalities with private sector and civil society are a condition for maximizing the outcomes of the interventions as presented in Figure 2.

Figure 2. Regional Development Scheme

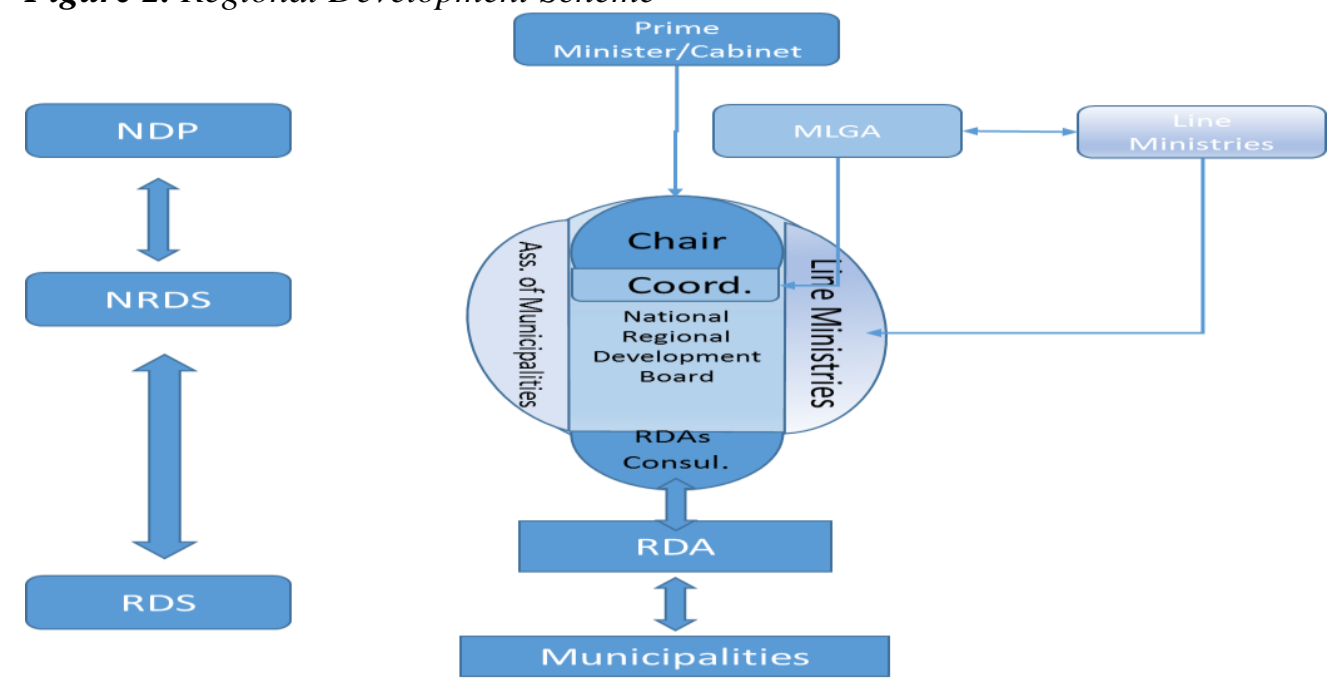

Bringing the private sector, academic and research institutions as well as social actors on board can be the best way to extend the dialogue and generate ownership and multiplier effects in the governance and in the outcomes of the development initiatives in the framework of the Regional Development Policy. RDAs can be empowered in application of the law on inter-municipal cooperation. Their enhancement can be realized bringing them into the institutional framework of the joint public-private partnership. A structure able to promote the development of a region and accountable for preparing the regional development or regional economic strategy as well as able to support the design, implementation, monitoring and evaluation of regional development projects is necessary for avoiding further duplications and ineffective use of the resources. Regional development implies coordination and contribution of all actors at different levels of responsibility.

\section{Conclusions and Recommendations}

There is not 'one size fits all' for regional development policies and strategies. A policy or a strategy, which has worked in one region, may not necessarily deliver in another. Different culture, political bias, unpreparedness of the actors, are just few possible aspects that can affect the success of the same approach into another 
context. The Regional Development policy for Kosovo needs to fit as a tailored suite for all the levels of governance in respect of the general principles described above.

The actual institutional framework is surely weak. It has been created in a different context where not all the principles could be applied and fulfilled. The structural mechanisms for this failure are relatively simple. If compared regional economic development to a clock, a well-designed and functioning development framework would move timely the two watch hands through a mechanism composed by a number of different toothed wheels moved by an engine. Institutional engine with efficient formal and informal institutions, propelling the clock moving its watch hands in the direction of development acting on the complex mechanism as a shared strategy among the actors. This coherence among the different levels and components allows a country and its territories to move forward and develop, minimizing the potential stickiness among the actors.

The path proposed to be followed is relatively simple. The political will to adopt a new leadership model with modern regional development structures will facilitate moving forward Kosovo out of its problems. This choice has only few degrees of freedom considering the internal and mainly the external factors that influence the policies. EU is and will remain the most close and committed partner of Kosovo and the process of accession cannot leave aside regional development. It is an opportunity for the whole country to establish a mechanism for using the regional development approach as propellant for change and development igniting the local energies and securing resources for it. The question should be neither if or why nor when but how. In the actual situation leadership may remain very often in the nivoeau of mechanic administration and this should be changed. Leadership and new decision making structures in the new regional development model in the country should be focused in a new approach that will support changes and will be able to address the issues.

The partial failure of actual Regional Development Agencies (RDAs) does not mean the failure of regional development in Kosovo and the failure is not only responsibility of RDAs. The inconsistence of the scheme with the weak support of the central level are the main culprits of the actual situation. Although it has not realized all the expected achievements, RDAs and regional development are a valuable experience for Kosovo. It has generated awareness, improved the capacities of local governments to deal with their development, and raised expectations that need to be addressed. It is now the time to review, to follow good practices and principles, to open the discussion about what the government and the local level can do for promoting and leading the process. It is now the moment to increase the level of cooperation between central and local level, between the local actors and the institutions shifting them from the position of policy taker into prosumers. The government of Kosovo is in the position to take the decision to embrace Regional Development as the method for joining the efforts to solve problems, generate opportunities, create employment and increase wealth. 


\section{References:}

Bachtler, J. \& Wren, C. 2009. Evaluation of European Union Cohesion policy: Research questions and policy challenges. Regional Studies, 40, 143-153.

Barca, F. 2009. An agenda for a reformed Cohesion Policy: A place-based approach to meeting European Union challenges and expectations. Independent report, prepared at the request of the European commissioner for regional policy. European Commission, Brussels.

Collinge, C., Gibney, J. \& Mabey, C. 2010. Leadership and place. Policy Studies, 31(4), 367-378.

EU Regional Development Strategy. 2016. Brussels.

EURED Report. 2017. Pristina.

Hirschman, A.O. 1958. The Strategy of Economic Development. Yale University Press, http://mzhe-ks.net/en/economic-development-and-european-integration.

Kosecik, M., Sagbas, I. 2007. Public attitudes to local government in Turkey: research on knowledge, satisfaction and complaints. Local Government Studies, 30(3), 360-383.

Kosovo Economic Profile. 2017.

Lewis, W.A, 1955. Theory of Economic Growth. Homewood, Illinois.

Niskanen, J. 2007. The Determinants of Firm Growth in Small and Micro Firms - Evidence on Relationship Lending Effects. University of Eastern Finland, Finland.

National Development Strategy of Kosovo 2016-2021. 2016. Pristina.

Nurkse, R. 1963. Problems of Capital Formation in Underdeveloped Countries. Oxford.

Porter, M. 1998, On Competition. Boston, Harvard Business School Press.

Richardson, H.W. 1973. Regional Growth Theory. London, MacMillan.

Rosenstein-Rodan, P.N. 1943. Problems of Industrialization of Eastern and Southeastern Europe. Economic Journal, June-September; and Notes on the Theory of the Big Push (mimeographed 1957).

Seitovsky, T. 1999. Two Concepts of External Economies. Journal of Political Economy, April.

Stimson, R.J., Robson, A., Stough, R.R. and Salazar, M. 2003. Leadership, Institutions and Regional Economic Development: A New Conceptual Framework. Paper to Pacific Regional Science Conference Organization, 18th Biennal Meeting, Acapulco, Mexico, July.

Stimson, R., Stough, R. \& with Salazar, M. 2009. Leadership and institutions in regional endogenous development. Cheltenham: Edward Elgar.

Yuill, D. et al. 2008. New Policy Frameworks, New Policy Approaches: Recent Regional Policy Developments in the EU and Norway. EoRPA Paper 08/1. 